\title{
Spousal Separation and Interpretation of Contraceptive Use and Unmet Need in Rural Nepal
}

Nepal has made considerable progress in improving the health of its population over the last two decades and is one of the few countries on track to meet Millennium Development Goals 4 and 5, which seek to reduce child mortality and improve maternal health. The total fertility rate has decreased by an average of two children per woman, from 5.1 in 1991 to 3.1 in 2006. During that period, the maternal mortality ratio also declined by $48 \%$, from 539 to 281 maternal deaths per 100,000 live births, and the infant mortality rate dropped by $39 \%$, from 79 to 48 deaths per 1,000 live births. ${ }^{1,2}$

These mortality declines can be attributed in part to increased family planning use..$^{3-5}$ Between 2001 and 2006, the proportion of married women in Nepal using any form of contraception increased from $39 \%$ to $48 \%{ }^{2,6}$ In 2006 , $18 \%$ of married women reported that they and their husband were protected against unintended pregnancy by female sterilization; smaller proportions reported using injectables (10\%), male sterilization ( $6 \%$ ), condoms (5\%), other modern methods (5\%) or traditional methods (4\%).

Despite the rise in contraceptive use between 2001 and 2006, data from the government health management information system suggest that, since 2006, use has leveled off or slightly declined..$^{7-9}$ This pattern is reflected in government data for all regions in Nepal. While these statistics could indicate problems in program performance, district program managers have commented to field staff that in their districts, most couples in need of family planning are being reached. How do we reconcile this apparent contradiction?

A study using data from the 2006 Nepal Demographic and Health Survey (NDHS) suggests that labor migrationrelated spousal separation* may have been one factor in the fertility decline in Nepal over the period 2001-2006. ${ }^{10}$ The study reported in this article considers family planning program performance as it is conventionally measured and, in light of data on spousal separation due to temporary labor migration, seeks to shed light on this important and growing demographic phenomenon.

Nepal has long experienced some degree of migration, particularly among males in search of short- and long-term work both within and outside the country. Seasonal migration to India has been common for some time, but in recent years, travel further afield and for longer periods has increased. According to government statistics, 1.4 million Nepalese citizens went to countries other than India for employment between 1993 and 2009. ${ }^{11}$ This figure probably underestimates the actual volume of migration. Data from the 2006 NDHS indicate that $37 \%$ of households reported that at least one adult member aged 15 or older had traveled away in the previous 12 months; the overwhelming majority likely did so to seek employment. ${ }^{12}$ Among households reporting any migration, an average of at least two adults had traveled away. Men were nearly three times as likely to have done so as women. Of the men who migrated, half (49\%) sought work elsewhere in Nepal, 37\% went to India and $14 \%$ migrated to other countries. Two-thirds were reported to have been away for more than six months. Also using 2006 NDHS data, Thapa reported that at the time of the survey, about $13 \%$ of the population (3.5 million people) had been away from home for more than six months. ${ }^{13}$

According to a 2008 survey, $44 \%$ of households in Nepal reported that at least one member was currently living either abroad or elsewhere in Nepal. ${ }^{14}$ That study found that $20 \%$ of individuals aged 15 and older (33\% of males and $7 \%$ of females) were living away from their usual place of residence. Consistent with the 2006 DHS findings, half of all absentees (51\%) were living outside Nepal.

Labor-related spousal separation is significantly more common in Nepal than in most other countries in the region. Data from Demographic and Health Surveys published between 2005 and 2007 show that the proportion of married women of reproductive age whose husbands live away was $4-5 \%$ in Vietnam and Cambodia and 9-12\% in India, Bangladesh and Pakistan, compared with Nepal's 26\%. ${ }^{15}$

Information on spousal separation has been collected in each NDHS since 1996. However, the 1996 survey had only one question on whether married couples were cohabiting. Subsequent surveys (2001 and 2006) included additional questions on spousal separation, providing an opportunity to analyze contraceptive use according to spousal residence status. These surveys have collected information from currently married women aged 15-49 on whether their husband was living at home or elsewhere and, if elsewhere, how long he had been away.

Demographers have long recognized that coital frequency and factors influencing it can come to bear on population-level fertility, and this has been reflected in demographic modeling specifically addressing spousal separation. ${ }^{16,17}$ There are also a small number of published empirical studies on spousal separation specifically, ${ }^{18-21}$ although none deals with monitoring family planning program performance in settings with increasingly high lev-

*In this Comment, "spousal separation" refers to married couples living apart due to temporary migration; the term is distinct from the DHS category "divorced or separated."

\section{By Bharat Ban, Sujan Karki, Ashoke Shrestha and Stephen Hodgins}

Bharat Ban is specialist and team leader for monitoring and evaluation, Sujan Karki is program officer for monitoring and evaluation and Ashoke Shrestha is project director, all at the Nepal Family Health Program, Kathmandu. Stephen Hodgins is technical director for the Maternal Child Health Integrated Program, John Snow, Inc., Washington, DC. 


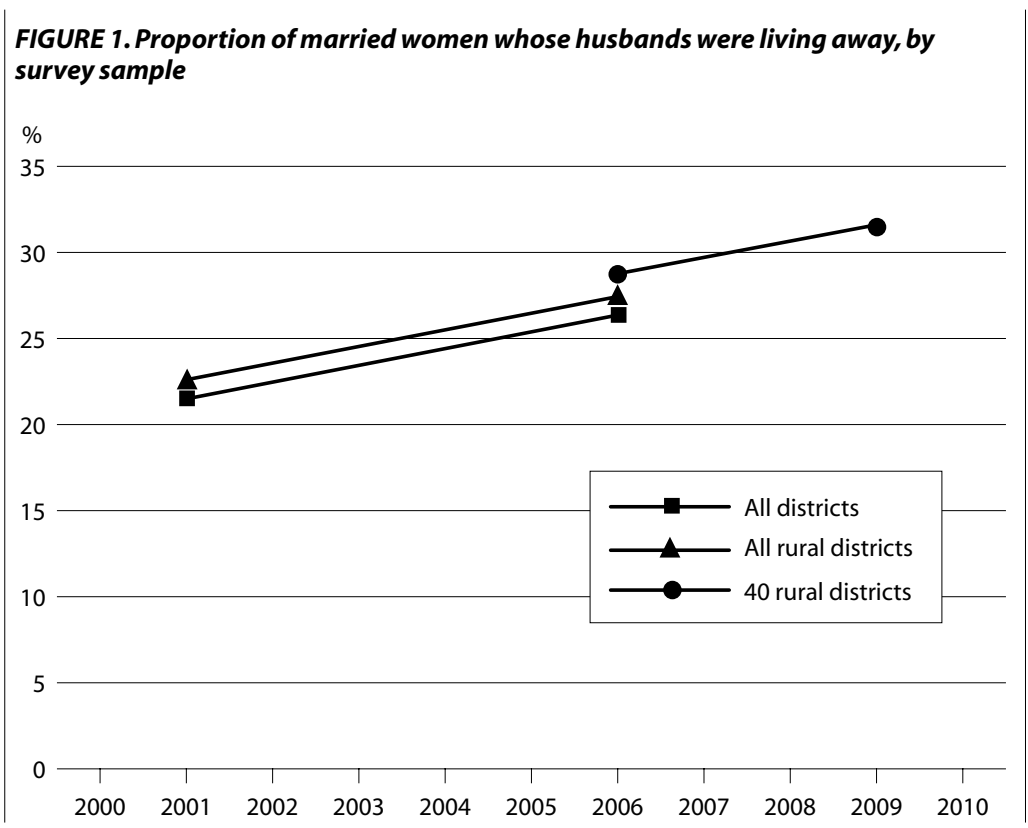

els of employment-related separation. Spousal separation does not necessarily imply an absence of coital activity; yet, the family planning needs of separated couples differ significantly from those who are cohabiting.

This Comment addresses the question of whether, in a setting with significant levels of spousal separation due to temporary labor migration, the usual population-level contraceptive prevalence and unmet need indicators adequately measure family planning program performance.

\section{METHODS}

We present results from a household survey conducted in 2009 as part of the U.S. Agency for International Development-funded Nepal Family Health Program-II (NFHP) survey, which focused on the rural population. The NFHP survey was modeled closely on the NDHS in content, sampling and analysis. The first author, who was also responsible for implementing fieldwork for the 2001 NDHS, led the survey work and the NFHP fieldwork was performed by New ERA, the organization responsible for implementing the 2001 and 2006 NDHS. Interviewers were, in many

*The sampling strategy involved including 20 NFHP program districts and 20 equivalent comparison districts, and was used to satisfy program evaluation objectives not addressed by this article.

tIn the 2006 NDHS, only $1 \%$ of wives of male household heads were reported to have migrated in the last 12 months, so they were excluded from the analysis.

$\ddagger$ Women with unmet need for spacing are those whose current pregnancy is mistimed; amenorrheic women who are not using family planning and whose last birth was mistimed, or whose last birth was unwanted but who now say they want more children; fecund women who are neither pregnant nor amenorrheic, who are not using any method of family planning, and say they want to wait two or more years for their next birth; and fecund women who are not using any method of family planning and say they are unsure whether they want another child or who want another child but are unsure when to have the birth. Women with unmet need for limiting are those whose current pregnancy is unwanted; amenorrheic women who are not using family planning, whose last child was unwanted and who do not want any more children; and fecund women who are neither pregnant nor amenorrheic, who are not using any method of family planning and who want no more children. cases, the same ones who fielded the 2006 NDHS.

The 2009 NFHP survey covered a purposively selected subset of 40 of Nepal's 75 districts. ${ }^{*}$ It was conducted in all of the rural clusters sampled in the 40 selected districts in the 2006 NDHS. The survey followed NDHS methodology, except that the household listing was done during, rather than before, the main survey. Although the rural population of these 40 districts is similar to the population of rural Nepal as a whole, this sample is not, strictly speaking, representative of rural Nepal. To inform national family planning program development in Nepal and to frame these results within a wider national context, we present limited urban and national data from earlier surveys.

We analyzed the data using SPSS 13.0 software. Because the NFHP study focused on only 40 districts, rather than on the whole country, we calculated new weights for the 2009 survey and also for the 2006 NDHS data on the rural clusters. Following the procedure used in Demographic and Health Surveys, we computed appropriate weights using records of population sizes of the clusters and the actual sample size drawn from each cluster, calculated by dividing each cluster's population weight (the cluster population divided by the total population from all clusters) by its sample weight (the total sample in the cluster divided by the total sample size for all clusters).

Among the goals of the 2009 NFHP survey was to assess contraceptive use and unmet need for family planning, according to spousal residence status. Spousal separation, in this paper, refers to cases of married (not divorced or legally separated) couples in which the woman reports that her husband is currently away. ${ }^{\dagger}$ The data were obtained from the Woman's Questionnaire in the 2006 NDHS and in the 2009 survey. Although spousal separation was originally a continuous variable, we have transformed it into a categorical variable: We combined all cases in which the husband has been absent for three or more months, although we acknowledge that there is still room for debate on what duration of spousal separation should be considered most appropriate as a threshold for examining unmet need. ${ }^{22}$ We chose this length of time in part to correspond with the three months of protection afforded by each injection of depot medroxyprogesterone acetate, the most commonly used nonpermanent contraceptive method in Nepal. For women using the injectable, three months would be the longest they could go before deciding whether to continue their method in their husbands' absence; for women using most other nonpermanent contraceptive methods, this decision would likely occur sooner. Therefore, three months may be a meaningful threshold above which couples' family planning needs may differ significantly according to whether they are cohabiting or separated.

To measure contraceptive use, we reported any method use (including sterilization and traditional method use) among married women of reproductive age (15-49). Likewise, we used the Demographic and Health Survey definition of unmet need, which includes unmet need for spacing and limiting. 
Analysis consisted of cross-tabulations, disaggregated by duration of husband's absence and using three months as a threshold. In looking at specific data, where we were interested in apparent changes in proportions between 2006 and 2009 or in comparing differences in changes over time between two different measures, we tested for significance using $z$ tests (or, in the few instances where means rather than proportions were compared, t tests).

\section{RESULTS}

\section{Trends in Spousal Separation}

In 2001, more than one-fifth (22\%) of husbands were living away from their wives ${ }^{6}$; the proportion increased to $26 \%$ in 2006 (Figure 1). ${ }^{2}$ Data on rural areas, from the 2006 NDHS and the 2009 NFHP survey, indicate that the proportion of currently married women who reported that their husbands were living away increased from 29\% in 2006 to $32 \%$ in 2009 ( $p<.01)$. The proportion of women who reported that their husband was not currently living with them was significantly lower in urban areas than in rural areas, though the gap had shrunk; 12\% of urban women reported their husband was living away in 2001, compared with 20\% in 2006 (not shown).

In the 2009 survey, nearly two-thirds (64\%) of cases of spousal separation were reported to have been for three or more months, and $47 \%$ for six or more months. In cases of separations of at least three months, $9 \%$ of the absent husbands were reported to be elsewhere in Nepal, 37\% in India and 54\% in other countries. Among husbands absent for six or more months, $65 \%$ were in countries other than Nepal or India.

\section{Use of Contraception}

Data from the 2009 survey indicate that among rural women not currently using a contraceptive method, 54\% reported the reason for nonuse as "husband not living at home" (not shown). In a setting where spousal absence is common and increasing, assessing family planning program performance using conventional measures of contraceptive prevalence and unmet need may be misleading. Therefore, we examined the potential differences in contraceptive prevalence according to spousal residence status and duration of absence.

Between 2001 and 2006, contraceptive use rose by nine percentage points (from $37 \%$ to $46 \%$ ) among all rural married women of reproductive age (Table 1), compared with a 13-point increase (from $42 \%$ to $55 \%$ ) among rural women whose husbands were residing at home. Between 2006 and 2009, among all married women in the 40-district rural sample, contraceptive use increased by a nonsignificant 1.7 percentage points, a plateau in use that is reflected in Government of Nepal statistics. However, this aggregate view masks a significant five-point increase (from $57 \%$ to $62 \%$ ) in family planning use among cohabiting couples, the segment of the population most at risk of unwanted or mistimed pregnancies. For this group, the rate of increase was approximately the same in 2006-2009
TABLE 1. Number of currently married women aged 15-49 and proportion using a contraceptive method, by sample and cohabitation status, according to survey, Nepal

Sample and $2001 \quad 2006 \quad 2009$

cohabitation status NDHS NDHS NFHP survey

\begin{tabular}{llll}
\hline All districts (N) & 8,342 & 8,257 & na \\
All & 39.3 & $48.0^{* * *}$ & na \\
Husband at home & 44.3 & $57.1^{* * *}$ & na \\
Husband away $<3$ mos. & 27.0 & $34.5^{*}$ & na \\
Husband away $\geq 3$ mos. & 16.3 & 14.1 & na \\
All rural districts (N) & 7,550 & 7,031 & na \\
All & 36.9 & $45.9^{* * *}$ & na \\
Husband at home & 41.7 & $54.8^{* * *}$ & na \\
Husband away $<3$ mos. & 26.3 & $33.6^{*}$ & na \\
Husband away $\geq 3$ mos. & 15.5 & 14.1 & na \\
40 rural districts (N) & & & \\
All & na & 4,021 & 3,825 \\
Husband at home & na & 47.9 & 49.6 \\
Husband away $<3$ mos. & na & 56.7 & $61.8^{* *}$ \\
Husband away $\geq 3$ mos. & na & 35.8 & 34.3 \\
\hline
\end{tabular}

*Difference between years significant at $p<.05$. ${ }^{* *}$ Difference between years significant at $p<.01$. ${ }^{* * *}$ Difference between years significant at $\mathrm{p}<.001$.

as it was in 2001-2006; meanwhile, rates of family planning use among non-cohabiting married couples remained flat over that period.

\section{Unmet Need for Contraception}

With increases in contraceptive use, overall unmet need in Nepal has declined steadily, from 31\% in 1996 (not shown) to $28 \%$ in 2001 and $25 \%$ in 2006 (Table 2). In the 40-district rural sample, little change occurred between 2006 and 2009 (from 24\% to 26\%). To examine this stagnation in level of overall unmet need, we estimated unmet need for couples according to husband's current residence status.

In 2001, when the proportion of households in which

TABLE 2. Number of currently married women aged 15-49 and proportion with unmet need, by sample and cohabitation status, according to survey, Nepal

Sample and

\begin{tabular}{llll}
$\begin{array}{llll}\text { Sample and } \\
\text { cohabitation status }\end{array}$ & $\begin{array}{l}2001 \\
\text { NDHS }\end{array}$ & $\begin{array}{l}2006 \\
\text { NDHS }\end{array}$ & $\begin{array}{l}2009 \\
\text { NFHP survey }\end{array}$ \\
\hline All districts (N) & 8,342 & 8,257 & na \\
All & 27.8 & $24.6^{*}$ & na \\
Husband at home & 23.8 & $16.3^{* * *}$ & na \\
Husband away $<3$ mos. & 36.9 & 38.9 & na \\
Husband away $\geq 3$ mos. & 46.9 & $54.0^{* *}$ & na \\
& & & \\
All rural districts (N) & 7,550 & 7,031 & na \\
All & 29.0 & $25.5^{*}$ & na \\
Husband at home & 25.1 & $17.2^{* * *}$ & na \\
Husband away $<3$ mos. & 37.5 & 38.8 & na \\
Husband away $\geq 3$ mos. & 47.2 & $53.4^{*}$ & na \\
& & & \\
40 rural districts (N) & na & 4,021 & 3,825 \\
All & na & 24.1 & $26.3^{*}$ \\
$\begin{array}{l}\text { Husband at home } \\
\text { Husband away }<3 \text { mos. }\end{array}$ & na & 15.6 & 15.2 \\
Husband away $\geq 3$ mos. & na & 36.1 & 36.4 \\
\hline
\end{tabular}

*Difference between years significant at $p<.05$. ${ }^{* *}$ Difference between years significant at $p<.01{ }^{* * *}$ Difference between years significant at $\mathrm{p}<.001$. 
TABLE 3. Number of currently married women aged 15-49, proportion who are pregnant or amenorrheic, and proportion of pregnancies classified as mistimed or unwanted, by sample, according to survey, Nepal

Sample and pregnancy status

All districts $(\mathbf{N})$

$\%$ of women pregnant or amenorrheic

$\%$ of pregnancies mistimed or unwanted

All rural districts $(\mathbf{N})$

$\%$ of women pregnant or amenorrheic

$\%$ of pregnancies mistimed or unwanted

40 rural districts $(\mathrm{N})$

$\%$ of women pregnant or amenorrheic $\%$ of pregnancies mistimed or unwanted

***Difference between years significant at $\mathrm{p}<.001$. +Significantly different from 2001 data on all districts and all rural districsts at $p<.001$. Samples are only roughly comparable. Note: The proportion of pregnancies classified as mistimed or unwanted is calculated according to DHS method.

the husband was living elsewhere was about one-third lower than in 2009, the measure of unmet need for all married women was only four percentage points higher than for women whose husbands were living at home. But, in the later surveys, with an increasing proportion of husbands away and increasing use of family planning by cohabiting couples (though not by couples separated for three months or more), unmet need among all married couples and unmet need among cohabiting couples diverge: In the 2009 survey, unmet need for family planning among cohabiting couples was 11 percentage points lower than that among all married couples (15\% vs. 26\%; $\mathrm{p}<0.001$ ). The lower levels of unmet need among cohabiting couples in the most recent surveys correspond with a significant decline over the same period in the proportion of women whose pregnancies were reported as either mistimed or unwanted, from $9-10 \% 2001$ to $6 \%$ in 2009 (Table 3). Comparisons between the 2009 40-district data and both national and rural NDHS 2001 data are significant at the level of $\mathrm{p}<.001$; these samples, however, are only roughly comparable.

One cannot assume that a couple has no risk of unintended pregnancy during a period of separation. In the 2009 survey, however, $92 \%$ of married female respondents whose husband lived with them reported sexual activity in the four weeks preceding the survey, compared with $0.1 \%$ among those whose husband had been away for at least

TABLE 4. Selected characteristics of cohabiting and noncohabiting married couples, by husband's migration status, Nepal, 2009

Characteristic

Cohabiting

Husband away Husband away

$<3$ mos.

$\geq 3$ mos.

No.

Mean age of woman (years)

Mean desired no. of children

Mean no. of living children

$\%$ of women with unmet need (spacing)

$\%$ of women with unmet need (limiting)

Total $\%$ with unmet need

$\begin{array}{rcr} & & \\ 2,622 & 432 & 771 \\ 32.4 & 28.3^{* * *} & 28.1^{* * *} \\ 2.4 & 2.3 & 2.2^{* * *} \\ 2.8 & 2.2^{* * *} & 2.1^{* * *} \\ 6.0 & 16.9^{* * *} & 14.8^{* * *} \\ 9.2 & 19.5^{* * *} & 43.5^{* * *} \\ 15.2 & 36.4^{* * *} & 58.5^{* * *}\end{array}$

***Difference from "at home" group significant at $\mathrm{p}<.001$ three months. The corresponding figures from the 2006 DHS were $82 \%$ and $0.2 \%$, respectively. Such self-reports may be subject to social desirability bias, but these results do suggest very little risk of unintended pregnancy during periods of spousal separation.

Beyond differences in need for family planning relating to coital frequency, cohabiting and noncohabiting couples differ in other respects. In comparison with couples in which the husband is temporarily living elsewhere, cohabiting couples are likely to be older and to have already achieved their desired family size (Table 4). Cohabiting couples are also more likely to be protected against pregnancy by the sterilization of one spouse (not shown)

\section{Conclusion and Discussion}

Nepal has experienced a relatively rapid increase in use of family planning, as documented by Demographic and Health Surveys in the last two decades. Simultaneously, spousal separation caused by migration for employment has increased. This second trend has made overall measures used for assessing performance of the country's family planning program less informative. To determine contraceptive prevalence and unmet need in such circumstances, disaggregating family planning use by the residence status of the husband gives a more complete picture of family planning need and use at the population level. Such disaggregated analysis, as presented here for Nepal, shows a more rapid rise in contraceptive use and a lower level of unmet need among women whose husband was living at home than do the conventional aggregated measures, which underestimate the extent to which the family planning program has been making progress in meeting the needs of the population.

Couples living apart cannot necessarily be considered to have no need for family planning, but their needs differ from those of couples who live together. In cases where husbands return home for brief periods, couples need some form of contraception to avoid a pregnancy. With increases in temporary, work-related migration, such circumstances are becoming more common. Family planning program managers need to adjust their strategies and approaches to ensure that the needs of such couples are effectively addressed, for example with increased emphasis on barrier methods and emergency contraception. Further exploratory work to better characterize the circumstances, needs and preferences of such couples would provide a necessary basis for designing and developing program approaches that better respond to the special needs of this group.

For family planning programs to effectively respond to changes in the populations they serve, they need a clear picture of clients' needs. Year-to-year monitoring of program performance, typically through Ministry of Health management information systems (possibly supplemented by program data from social marketing agencies and NGOs involved in direct service provision), can give a reasonable approximation of populatioin-wide levels and trends in 
family planning use in settings where spousal separation is not prevalent, but may be lacking where spousal separation is common. In countries or subnational regions with high levels of spousal separation, we would recommend using disaggregated data, such as that presented here, for monitoring program performance.

Furthermore, Ministry of Health data cannot tell us what proportion of married couples need to use an ongoing family planning method to avoid an unwanted or mistimed pregnancy, particularly in circumstances in which many husbands are away. Household survey methods can help fill this gap. The gold standard for such purposes is the Demographic and Health Survey. However, the cost and complexity of this survey precludes using it more frequently than every five years or so. This paper reports results of a large household survey that, while not fully national, gives a good sense of levels and trends and useful guidance to program managers in the country. The survey was conceived as a "midterm" survey to provide a window on progress across a range of maternal-child health and family planning issues. Program managers in other countries may want to consider the use of such midterm surveys. If there is in-country technical capacity, such surveys can be done at relatively modest cost.

\section{REFERENCES}

1. Pradhan A et al., Nepal Family Health Survey 1996, Kathmandu, Nepal: Ministry of Health; and Calverton, MD, USA: Macro International, 1997.

2. Nepal Ministry of Health and Population (MOHP), New ERA and Macro International, Nepal Demographic and Health Survey 2006, Kathmandu, Nepal: MOHP and New ERA; and Calverton, MD, USA: Macro International, 2007.

3. Stover J and Ross J, How increased contraceptive use has reduced maternal mortality, Maternal and Child Health Journal, 2010, 14(5):687-695.

4. Alam N, Birth spacing and infant and early childhood mortality in a high fertility area of Bangladesh: age-dependent and interactive effects, Journal of Biosocial Science, 1995, 27(4):393-404.

5. Ronsmans C, Birth spacing and child survival in rural Senegal, International Journal of Epidemiology, 1996, 25(5):989-997.

6. Nepal Ministry of Health, New ERA and ORC Macro, Nepal
Demographic and Health Survey 2001, Calverton, MD, USA: ORC Macro, 2002

7. MOHP, Annual Report 2005/06, Kathmandu, Nepal: MOHP, 2007.

8. MOHP, Annual Report 2006/07, Kathmandu, Nepal: MOHP, 2008.

9. MOHP, Annual Report 2007/08, Kathmandu, Nepal: MOHP, 2009.

10. Karki YB and Krishna R, Factors Responsible for the Rapid Decline of Fertility in Nepal-An Interpretation: Further Analysis of the 2006 Nepal Demographic and Health Survey, Calverton, MD, USA: Macro International, 2008.

11. Ministry of Labor and Transport Management, Department of Foreign Employment, Numbers of Nepalese workers travel ing abroad for foreign employment after obtaining official approval between July 1994 and June 2006 (Table 1) and July 2006 and June 2011 (Table 2), 2011, <http://www.dofe.gov.np/uploads/ Final\%20Data\%20of\%202050_51\%20to\%20\%202066_67.pdf> accessed June 6, 2012 (in Nepali).

12. Special tabulations of data from the 2006 Nepal Demographic and Health Survey.

13. Thapa S, Declining trends of infant, child and under-five mortality in Nepal, Journal of Tropical Pediatrics, 2008, 54(4):265-268.

14. Central Bureau of Statistics (CBS), Report on the Nepal Labour Force Survey 2008, Kathmandu, Nepal: CBS, 2009

15. Special tabulations of data from Measure DHS, <www.measuredhs.com/data/available-datasets.cfm>, accessed Feb. 2, 2010.

16. Bongaarts J and Potter RG, Fertility effect of seasonal migration and seasonal variation in fecundability: test of a useful approximation under more general conditions, Demography, 1979, 16(3):475-479.

17. Millman SR and Potter RG, The fertility impact of spousal separation, Studies in Family Planning, 1984, 15(3):121-126.

18. Myntti C, Population processes in rural Yemen: temporary emigration, breastfeeding, and contraception, Studies in Family Planning, 1979, 10(10):282-289.

19. Massey DS and Mullan BP, A demonstration of the effect of seasonal migration on fertility, Demography, 1984, 21(4):501-517.

20. Blanc AK, The role of conflict in the rapid fertility decline in Eritrea and prospects for the future, Studies in Family Planning, 2004, 35(4):236-245

21. Clifford D, Spousal separation, selectivity and contextual effects: exploring the relationship between international labor migration and fertility in post-Soviet Tajikistan, Demographic Research, 2009, 21(32):945-975.

22. Stash S, Explanations of unmet need for contraception in Chitwan, Nepal, Studies in Family Planning, 1999, 30(4):267-287.

Author contact:shodgins@mchip.net 